\title{
Phytoremediation of Lead by Vigna mungo
}

\author{
Mani Jain, Rupali Barnwal, Pammi Gauba \\ Department of Biotechnology, Jaypee Institute of Information Technology, Noida, Uttar Pradesh, India \\ Address for Correspondance: Pammi Gauba, pammigauba@hotmail.com
}

\section{Keywords}

Phytoremediation;

Translocation;

Heavy Metals.
ABSTRACT: In present scenario, heavy metals are an increasing ecological threat which is commonly results from human activities. Mining and the use of synthetic products (batteries, pesticides etc) can result in heavy metal contamination of agricultural soil and water environment. Several methods are already being used to remediate metal contaminated soils but they destroy the biotic components of soil causes secondary pollution and expensive to implement. In contrast, phytoremediation is the most effective, low cost and environmental friendly technology in which plants and their associated microbial flora are used to remediate metal ions from polluted areas. On the basis of these two factors, translocation (TCF) and bio concentration factor $(\mathrm{BCF})$ the plant termed as hyper-accumulated plant. An investigation was conducted to study the heavy metal $\mathrm{Pb}$ accumulation capacity in a fast growing plant vigna mungo. The plant fed up with different concentration of heavy metal solution such as $100 \mathrm{ppm}, 200 \mathrm{ppm}, 300 \mathrm{ppm}, 400 \mathrm{ppm}$ and $500 \mathrm{ppm}$ for a period of 30 days in culture test tubes. The lead content in vigna mungo was quantified. The phytoremediation of lead using vigna mungo showed that in 3 weeks the plant remediated $99.68 \%$ of lead. C 2016 iGlobal Research and Publishing Foundation. All rights reserved.

Conference Proceedings: International Conference on Advances in Plant and Microbial Biotechnology (PMB-2017); JIIT, Noida: February 02-04, 2017

Indo Global Journal of Pharmaceutical Sciences( ISSN 22491023 ; CODEN- IGJPAI; NLM ID: 101610675) indexed and abstracted in EMBASE(Elsevier), SCIRUS(Elsevier),CABI, CAB Abstracts, Chemical Abstract Services(CAS), American Chemical Society(ACS), Index Copernicus, EBSCO, DOAJ, Google Scholar and many more. For further details, visit http://iglobaljournal.com 